\title{
Posterior callosal section in a non-epileptic patient
}

\author{
ANTONIO R DAMASIO, HELENA C CHUI, JAMES CORBETT, \\ AND NEAL KASSEL \\ From the Department of Neurology (Division of Behavioral Neurology and Benton Laboratory of \\ Neuropsychology), and Department of Surgery (Division of Neurosurgery), University of Iowa \\ College of Medicine, Iowa City
}

SUMMARY The major studies of the effects of callosal section in humans have been conducted in severe epileptic patients in whom commissurotomy has been performed for management of intractable seizures. ${ }^{12}$ In spite of the evidence which has been amassed it is possible to criticise the results, on the grounds that all patients had seizures for many years prior to surgery and hence it is conceivable that some adaptive reorganisation of the epileptic brain might account for the different behaviour of the two hemispheres. Specifically, since the primary epileptic focus and its possible underlying focal damage are often asymmetric, one hemisphere might have had to adapt to the functional deficit of the other and thereby produce the basis for the unusually striking hemispheric differences. The answer to these reservations must come from the study of non-epileptic subjects who undergo some form of commissurotomy for reasons other than treatment of seizures, particularly if the intervention involves the posterior third of the corpus callosum, the sector considered responsible for the more remarkable "disconnection" signs. Only seven such cases have been reported. ${ }^{3-6}$ Here we report findings in a non-epileptic and previously normal 16-year-old boy who underwent section of the splenium for exploration of a pineal tumour. Our results indicate that surgical section of the splenium produced visual disconnection signs comparable to those seen in epileptic patients with complete commissurotomy.

\section{CASE REPORT}

The patient is a 16-year-old white boy, right handed, a high school junior. He presented to University Hospitals complaining of progressive headaches over a period of three months. He described the headaches as throbbing and located in the occiput or vertex, but occasionally generalised. They were associated with neck stiffness and were aggravated by cervical flexion. During the month preceding admission, the patient noted blurred vision and diplopia, and in the two weeks prior to his first visit the headaches became more frequent, more severe, and were accompanied by nausea and vomiting. Burning eye pain and dizziness, especially in the morning upon arising, also appeared.

On admission the patient was afebrile and alert. The general examination was remarkable only for bilateral submandibular lymphadenopathy. There was resistance to neck flexion. Pupils

Address for reprint requests: Dr AR Damasio, M.D., Department of Neurology, University of Iowa Hospitals, Iowa City, Ioiva 52242, USA.

Accepted 24 October 1979 reacted poorly to light but well to accommodation. There was a mild skew deviation and vertical nystagmus on up-gaze. The patient reported diplopia. The optic disc margins were indistinct nasally, venous pulsations were absent, and a haemornhage was present in the right disc. Visual acuity $(20 / 40$ OU), visual fields assessed by confrontation, and the function of the remaining cranial nerves were intact. Muscle tone, strength, and stretch reflexes were normal. Plantar responses were flexor. Sensory and cerebellar examination were unremarkable. Sphinctor function was intact.

Complete blood count, SMA $6 / 60$ and 12/60 were normal. Lumbar puncture was performed and the opening pressure was $300 \mathrm{~mm} \mathrm{H}_{2} \mathrm{O}$. The cerebrospinal fluid was clear and contained $65 \mathrm{lym}$ phocytes, 3 histiocytes, and 3 red blood cells per $\mathrm{mm}^{3}$. Protein was significantly elevated at $1.23 \mathrm{~g} / 1$. Glucose $3.27 \mathrm{mmol} / 1 \quad(59 \mathrm{mg} \%)$ and chloride $(127 \mathrm{mg} \%)$ were normal, as was the cell count.

An amorphous calcification in the midline, 1 $\mathrm{cm}$ in diameter, was seen on skull radiographs. On computerised tomography, this proved to lie 


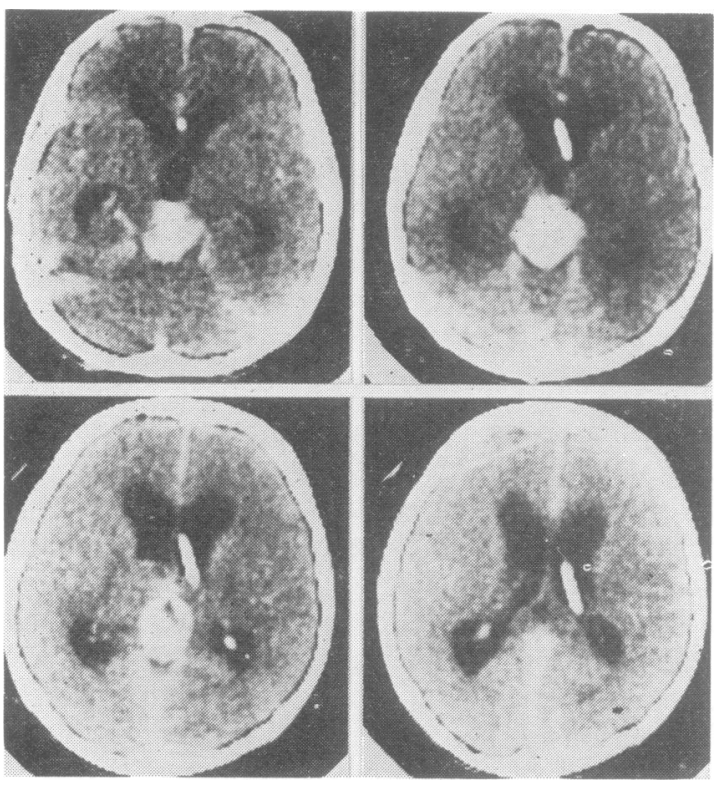

Fig $C T$ scan ( $a, b$ and $c$ ) shows round high density area in pineal region. The dorsum of the splenium, probably compressed from below, can be seen in the higher cut (d).

within a 4 by $4 \mathrm{~cm}$ mass in the region of the pineal gland, a mass that enhanced with contrast. In addition, there was moderate dilatation of the lateral and third ventricles (fig). Distortion of the middle and posterior portion of the internal cerebral vein was shown by arteriography.

Dexamethasone was immediately started and a right lateral ventricular shunt was placed. The headaches subsided. The following week, a right parieto-occipital craniotomy was performed. The right parietal lobe was retracted laterally, and the posterior portion of the splenium of the corpus callosum was sectioned longitudinally. The entire incision was approximately $1.5 \mathrm{~cm}$ in length. A light grey, gelatinous tumor was exposed, lying immediately below the splenium, spreading to the internal cerebral veins bilaterally, and extending into the third ventricle. A biopsy was obtained.

Histopathology showed cords and nests of moderately atypical large cells with vesicular nuclei and abundant amphophilic cytoplasm. Lymphocytes were distributed amongst narrow collagenous trabeculae. The suggested diagnosis was atypical teratoma (seminoma).

The postoperative course was unremarkable, except for a left parotitis which was treated with penicillin, and radiation therapy to a total dosage of 5500 rads to the primary tumor site and 3500 rads to the entire spinal axis was administered. The patient resumed normal school activities.

\section{Behavioural study}

1. General Evaluation The patient was studied in six different sessions, which took place at 14, 15, $16,28,35$ and 70 days after operation. His return to full school activities precluded the continuation of testing sessions. He was oriented and cooperative at all times. He appeared appropriately concerned with his condition and with his future although not depressed. Except for some mild fatigue and a reduction of speed in reading ability, he had no complaint and thought nothing had changed in him, physically or mentally. Speech was well articulated, fluent, prosodic and without paraphasic errors. Verbal intelligence assessed by the Wechsler Adult Intelligence Scale was average $(\mathrm{IQ}=100)$.

Naming of objects in the tactile modality (using the tactile naming test of the Neurosensory Center Comprehensive Examination of Aphasia ${ }^{7}$ ) placed in either the right or left hand with the subject blindfolded was normal, suggesting that interhemispheric transfer of tactile information was intact.

Pure tone audiometry was unremarkable. A relative extinction of the left ear in a verbal dichotic listening task was present at two weeks after surgery but no extinction could be demonstrated two months later. Praxic ability was normal.

2. Study of Visual Function Following surgery the patient's sole visual complaint was a subjective slowing in reading ability. Nevertheless he was able to read at a college graduate level as assessed by the Wide Range Achievement Test. Later he reported improvement of this defect.

Global visuoperceptive ability was assessed by the tests of Facial Recognition ${ }^{8}$ and Judgment of Line Orientation. ${ }^{9}$ The patient scored in the normal range in both.

Neuro-ophthalmological evaluation was carried out on two occasions. Specific testing included kinetic Goldmann perimetry using $I_{2 \mathrm{e}}$ and $I_{4 \mathrm{e}}$ isopters, which was normal, Farnsworth-Munsell 100 hue test, which revealed a mild deuteranomaly (as present in $7 \%$ of men), and testing for Pulfrich stereo-phenomenon which was also normal. Visual acuity was $10 / 15$ in both eyes. Since intactness of the visual field would be a major factor in the performance of tachistoscopic tasks, and in spite of the normal fields reported on confrontation and on Goldmann perimetry, it 
was decided to use static perimetry as well. This proved to be entirely normal, in the $0-180^{\circ}$ axis. In summary, except for a mild deutenanomaly (defect to green) no evidence of visual dysfunction could be detected with neuro-ophthalmologic examination techniques.

Study of interhemispheric transfer of visual information was carried out in a Three Channel Tachistoscope Model GB of the Scientific Prototype Manufactoring Company. This equipment allows effective addressing of visual stimuli to either the left or right visual field, by limiting the duration of stimulus exposure, and circumventing the problem of quick saccadic refixation. The patient was adapted to darkness for several minutes. Visual fixation was directed at a black point centrally located in one of the channels. Stimuli were presented to either the left or right visual fields, or in both fields simultaneously. The field chosen for stimulus presentation was altered in a random sequence. Identical stimuli were exposed in each field randomly during the course of a testing session. Stimulus duration was $100 \mathrm{~ms}$ or less. The sizes and peripheral loci of the stimuli varied. In general they subtended $0.5-1.5$ degrees vertically and were situated 1-2.5 degrees lateral to fixation. All responses to test stimuli were verbal. For certain tasks the latency of response was measured from the onset of stimulus exposure until the time the patient initiated a response. Specific tasks included reading of verbal stimuli, naming of simple and complex pictures of objects or scenes, judgment of line orientation, and judgment of emotional facial expressions.

Reading of single letters disclosed a minimal and nonsignificant superiority of the right visual field over the left field $(98 \%$ versus $85 \%$, percentage of correct responses). Reading of single digits showed even less difference, near perfect scores being obtained bilaterally.
In striking contrast there was a significant superiority of the right visual field in the reading of three letter words. The latter were of the consonant-vowel-consonant form. This task was administered on six occasions spanning a period of two months. The average number of correct responses to words seen in left visual field was $0 \cdot 36$ (standard deviation $=0 \cdot 10$ ). This contrasted with an average of 0.99 (standard deviation $=0.08$ ) for stimuli presented to the right field. The difference was statistically significant $(\mathrm{p}<0.01)$ (table).

A similar difference was reflected in the latencies of response. Mean response times for the left and right visual fields were, respectively, $3.5 \mathrm{sec}$ (standard deviation $=1.2$ ) and $1.2 \mathrm{sec}$ (standard deviation $=0 \cdot 20$ ). This difference also was significant $(\mathrm{p}<0.001)$ (table). Considering the latencies of the correct responses only, thus eliminating the possibility that delays might be more prolonged for incorrect responses, the differences remained constant and significant $(\mathrm{p}=0.001)$.

Object naming was evaluated using both simple visual stimuli (simplified line drawings) and complex visual stimuli (magazine coloured photographs). A superiority of the right visual field was evident for both. In the first condition, $66 \%$ of 36 figures were correctly named in the left visual field versus $88 \%$ on the right side. In the condition of complex stimuli, the number of test samples (10) was too small for differences to be treated statistically. However, qualitative analysis of the performances showed remarkable differences. Whereas only a single stimulus $(10 \%)$ was interpreted correctly when presented to the left visual field, six $(60 \%)$ were described correctly when appearing on the right. Also a stimulus first presented in the right visual field and appropriately interpreted, always would next produce no response when given to the left.

Table Performance of left and right visual fields

\begin{tabular}{|c|c|c|c|c|c|c|c|}
\hline \multirow[t]{2}{*}{ Task } & \multicolumn{3}{|c|}{ Left visual field } & \multicolumn{3}{|c|}{ Right visual field } & \multirow[b]{2}{*}{$\begin{array}{l}\text { Significance } \\
\text { of } \\
\text { difference }\end{array}$} \\
\hline & $\begin{array}{c}\text { Raw } \\
\text { score }\end{array}$ & $\begin{array}{l}\text { Per cent } \\
\text { correct }\end{array}$ & $S D$ & $\begin{array}{l}\text { Raw } \\
\text { score }\end{array}$ & $\begin{array}{l}\text { Per cent } \\
\text { correct }\end{array}$ & $S D$ & \\
\hline $\begin{array}{l}\text { Reading of digits } \\
\text { Reading of letters } \\
\text { Reading of words } \\
\text { Average response delay } \\
\text { Naming of simple drawings of objects } \\
\text { Naming of magazine photographs } \\
\text { Judgment of line orientation } \\
\text { Average response delay } \\
\text { Identification of "emotional" faces } \\
\text { Average response delay }\end{array}$ & $\begin{array}{l}33 / 30 \\
46 / 54 \\
40 / 108 \\
- \\
24 / 36 \\
1 / 10 \\
24 / 35 \\
-9 / 10 \\
-\end{array}$ & $\begin{array}{l}0 \cdot 92 \\
0.85 \\
0 \cdot 36 \\
3 \cdot 52 \mathrm{~s} \\
0.66 \\
0 \cdot 10 \\
0.69 \\
5 \cdot 7 \mathrm{~s} \\
0.9 \\
3 \cdot 1 \mathrm{~s}\end{array}$ & $\begin{array}{l}\overline{-} \\
\overline{(0 \cdot 01)} \\
(1 \cdot 20) \\
\overline{-} \\
\overline{(2 \cdot 90)} \\
\overline{(1 \cdot 3)}\end{array}$ & $\begin{array}{r}35 / 36 \\
53 / 54 \\
107 / 108 \\
-\quad \\
32 / 36 \\
6 / 10 \\
26 / 35 \\
-\quad 5 / 10 \\
-\end{array}$ & $\begin{array}{l}0.97 \\
0.98 \\
0.99 \\
1.2 \mathrm{~s} \\
0.88 \\
0.60 \\
0.74 \\
3.0 \mathrm{~s} \\
0.5 \\
3.4 \mathrm{~s}\end{array}$ & $\begin{array}{l}- \\
\overline{(0 \cdot 077)} \\
(0 \cdot 20) \\
- \\
- \\
\overline{(1 \cdot 48)} \\
\overline{(0 \cdot 67)}\end{array}$ & $\begin{array}{l}\text { NS } \\
\text { NS } \\
p<0.01 \\
p<0.001 \\
\text { NS } \\
- \\
\text { NS } \\
p<0.001 \\
\overline{N S}\end{array}$ \\
\hline
\end{tabular}

$\mathrm{NS}=$ non-significant $; \mathrm{SD}=$ standard deviation. 
In the task of judgment of line orientation? the subject was presented with one of eleven lines positioned on a display at $18^{\circ}$ angles from one another. After a one second interval, a key displaying all eleven lines numbered consecutively, was flashed and the patient asked to select the line previously seen by calling out its number. The proportion of correct responses was identical for lines seen in the left visual space and for those seen in the right visual space. On the other hand, the mean latency of response was greater for the stimuli projected in the left field (5.7) as compared to 3.0 for those in the right field, a difference significant for $\mathrm{p}<\cdot 001$.

Judgment of emotional facial expression: Polaroid photographs of persons simulating the facial expressions usually associated with joy, sadness, anger, fear, and pain were exposed for $100 \mathrm{~ms}$ in either visual field. Credit was given for responses that were in general concordance with either a "negative" or "positive" emotion. Although the number of stimuli (10) was insufficient for quantitative analysis, qualitative appreciation of performance suggested that reporting was better for faces seen in the left visual field. Cross errors occurred on presentations to the right visual field only (for example in three instances a "happy" face was interpreted as "sad" or vice-versa).

\section{Discussion}

The surgeon's estimate of splenial section was approximate, given the restricted view of the area, but it appears likely that the whole splenial bulb was sectioned in order to reach the pineal mass. Even though the shape of the splenium varies considerably from subject to subject, it appears likely that a midline $1.5 \mathrm{~cm}$ longitudinal section would have destroyed all or most of the interhemispheric visual fibres. Indeed, it is even possible that some auditory fibres which cross in a position immediately anterior to the visual ones (as suggested by the studies of Pandya et $\left.a l,{ }^{10}\right)$ might also have been destroyed. For this reason a dichotic listening test was administered in order to find out whether or not the patient had a "paradoxical" left ear extinction known to be associated with callosal disconnection. ${ }^{11^{-13}}$ Shortly after the operation the patient did show an inferiority of the left channel which possibly indicated dysfunction in interhemispheric auditory pathways, but when the test was repeated the pattern of dichotic listening was normal suggesting that the abnormality had been transient. We conclude that auditory fibres were disturbed but not destroyed, in the postoperative period, and recovered later on.

The interhemispheric somatosensory fibres, which cross more anteriorly in the callosum, ${ }^{10}$ should have been intact, so that no disturbance of praxis or naming in the left hand should have been present. In fact, that was the case and the patient exhibited normal tactile naming in either hand immediately after the operation. The restriction of behavioural defects to the visual realm is consistent with the assumption that visual fibres but not auditory or somatosensory ones, were destroyed by the operation.

The subject's performance in visual tasks was comparable to that described in epileptic patients after a complete callosotomy. ${ }^{1}$ The striking sign of disconnection appeared in the tasks of object naming. Even after the subject had seen a given visual stimulus with his left hemisphere and had named it appropriately, he was unable to produce any verbal response when the stimulus was presented to the right hemisphere. The phenomenon indicated a lack of "cross-talk" between the hemispheres, and its magnitude cannot be explained by mere asymmetry of brain function. The generally lower quantity and quality of verbal responses given to stimuli directed at the right hemisphere, can be explained by the inability to transfer most visual information arriving in the right hemisphere to the verbally competent left half of the brain, combined with the right hemisphere's limited verbal competence. Given the short duration of the disease these behavioural asymmetries cannot be explained by a special form of adaptive cerebral development as could be invoked in patients with seizures.

This boy's performance also was similar to that in the comparable case reported by Gazzaniga and Freedman ${ }^{5}$ : in both, naming of objects seen in the right hemisphere was impaired. In this aspect, the cases appear different from that of Maspes $^{4}$ and from some cases of pure alexia. ${ }^{14}$ But the discrepancy may be an artefact. On the one hand the techniques used in Maspes' study were not comparable to the ones currently used and, on the other, although naming of three dimensional objects can be preserved in pure alexia, naming of the corresponding 2 dimensional pictures tends to be impaired. ${ }^{15}$ Our findings also were similar to those reported by Iwata and collaborators. ${ }^{6}$

What is the interpretation of the impoverished but by no means nonexistent ability of the right hemisphere either to fully process, or at least originate, some verbal responses? The fact that 
verbal responses appeared at all suggests that either the right hemisphere was capable of some language comprehension and expression, or that the right hemisphere was capable of some linguistic processing but relied on residual transfer, to the left, for the purpose of linguistic expression.

That the right hemisphere is capable of some linguistic processing which stops short of propositional expression has been demonstrated in split-brain patients ${ }^{16}$ and in a case of left hemispherectomy. ${ }^{17}$ In our case the verbal expression shown to stimuli directed at the right hemisphere goes beyond that seen in the splitbrain or hemispherectomy cases. The motor aspect of the responses, in all likelihood, originated in the left hemisphere, which suggests that some interhemispheric transfer capacity remained. Such capacity could be related to (a) sparing of some visual fibres in the splenium, (b) rerouting of information transfer to an anterior sector of the callosum, using an alternative information mode, or (c) utilisation of the intact anterior commissure. All three explanations appear reasonable but regarding the first one we have no reason to believe that any fibres were spared in the splenium. Rerouting of information appears likely since intermodal transfer within the isolated minor hemisphere has been demonstrated clearly in split-brain patients. ${ }^{18}$ Finally some evidence could be marshalled to support the hypothesis that the anterior commissure is an effectual interhemispheric conveyor of noncomplex visual information (see Risse, et al, ${ }^{19}$ for recent data on anterior commissure and Geschwind, ${ }^{14}$ for discussion on the role of anterior commissure in partial commissurotomy in man). The fact that all responses related to right hemisphere processing were delayed is consistent with the notion of rerouting and transfer either in the rostral callosum or the anterior commissure. In fact, considering all the potential for cross-modal intra-hemispheric convergence of information and all the potential for interhemispheric transfer resulting from the preservation of most of the callosum and the anterior commissure, it is remarkable that disconnection signs appeared at all. That they did, reflects how the basic processing of certain visual stimuli and certain visual tasks remains confined to visual cortex, without viable cross-modal diffusion.

By isolating one hemisphere from another, a partial or complete callosal section highlights the functional weaknesses and strengths of each of the sides of the brain. This study once again demonstrates the absolute superiority of the left hemisphere for verbal processing, though it also supports the notion that the right hemisphere, in spite of severe limitations, is capable of some verbal processing. For visual non-verbal processing, the results show how both hemispheres are capable of high level performance albeit with some right hemisphere superiority. The fact that a verbal response was always required, limited the assessment of right hemisphere performance and it is possible that a more pronounced superiority might have been seen if different testing conditions had been possible. In addition, had there been a possibility of giving an appropriate number of presentations in the test of emotional facial recognition, we suspect an absolute superiority of the right hemisphere would have appeared.

\section{References}

1 Gazzaniga JE, Bogen JE, Sperry KW. Observations on visual perception after disconnexion of the cerebral hemispheres in man. Brain 1965; 85:221-36.

2 Wilson DH, Reeves AG, Gazzaniga MS, Culver C. Cerebral commissurotomy for the control of intractable seizures. Neurology (Minneap) 1977; 27:708-15.

3 Treschner JH, Ford RF. Colloid cyst of the third ventricle. Archives of Neurology and Psychiatry (Chicago) 1937; 37:959-73.

4 Maspes PE. Le syndrome experimental chez l'homme de la section du splenium du corps calleux. Alexie visuelle pure hemianopsique. Rev Neurol (Paris) 1948; 80:100-13.

5 Gazzaniga MS, Freedman H. Observations on visual processes after posterior callosal section. Neurology (Minneap) 1973; 23:1126-30.

6 Iwata M, Sugishita M, Toyokura Y, Yamada R, Yoshioka M. Étude sur le Syndrome de Disconnexion Visuo-Linguale aprés la Transection du Splenium du Corps Calleux. J Neurol Sci 1974; 23:421-32.

7 Spreen O, Benton AL. Neurosensory Center Examination for Aphasia (NCCEA), Victoria, British Columbia: University of Victoria, 1969.

8 Benton AL, Van Allen MW. Impairment in facial recognition in patients with cerebral disease. Cortex 1968; 4:344-58.

9 Benton AL, Hannay HJ, Varney NR. Visual perception of line direction in patients with unilateral brain disease. Neurology (Minneap) 1975; 25:907-10.

10 Pandya DN, Karol EA, Heilbronn D. The topographical distribution of interhemispheric projections in the corpus callosum of the rhesus monkey. Brain Res 1971; 32:31-43.

11 Sparks R, Geschwind N. Dichotic listening in man after section of neocortical commissures. Cortex 1968; 4:3-16.

12 Milner B, Taylor L, Sperry RW. Lateralised 
suppression of dichotically presented digits after commissural section in man. Science 1968; 161:184-5.

13 Damasio H, Damasio AR. "Paradoxic" ear extinction in dichotic listening: Possible anatomical significance. Neurology (Minneap) 1979; 29:644-53.

14 Geschwind N. Disconnexion syndromes in animals and man. Brain 1965; 88:237-94, 585644.

15 Damasio AR, McKee J, Damasio H. Determinants of performance in color anomia. Brain Lang 1979; 7:74-85.
16 Gazzaniga MS, LeDoux JE. The Integrated Mind. New York: Plenum Press, 1978.

17 Smith A, Burklund CW. Dominant hemispherectomy. Science 1966; 153:1280.

18 Sperry RW, Gazzaniga MS, Bogen JE. Interhemispheric relationships: the neocortical commissures; syndromes of hemisphere disconnection. In: Handbook of Clinical Neurology 1969; 4:273-90.

19 Risse GL, LeDoux, Springer SP, Wilson DH, Gazzaniga MS. The anterior commissure in man: Functional variation in a multisensory system. Neuropsychologia 1978; 16:23-31. 